\title{
Las cooperativas de crédito españolas y la lucha contra la exclusión financiera
}

\author{
Luis Jesús Belmonte Ureña ${ }^{\star}$ Francisco Joaquín Cortés García ${ }^{\star *}$, Valentín Molina Moreno ${ }^{\star * *}$
}

* Doctor en Economía y Empresa. Profesor del Departamento de Economía Aplicada, Universidad de Almería, España.

\section{Correo electrónico:}

lbelmont@ual.es

* Doctor en Teoría Superior de la Economía. Gestor de Responsabilidad Social Corporativa, Fundación Cajamar Caja Rural.

\section{Correo electrónico:}

franciscojoaquincortesgarcia@ gmail.com

*** Doctor en Ciencias Económicas Empresariales. Magíster en Gestión de Cooperativas. Profesor de la Facultad de Ciencias Económicas y Empresariales, Universidad de Granada, España.

Correo electrónico: valentinugr1@gmail.com

Recibido: 14 de enero del 2013

Aprobado: 29 de agosto del 2013

Cómo citar este artículo: Belmonte Ureña, L.J., Cortés García, F.J. y Molina Moreno, V.

(2013). Las cooperativas de crédito españolas y la lucha contra la exclusión financiera. Cooperativismo \& Desarrollo, 21 (103), 49-55.

\begin{abstract}
Resumen
El objetivo de este trabajo consiste en presentar la importancia del sector de cooperativas de crédito en España, al tiempo que se ofrece una breve visión de la evolución de las pautas de ahorro financiero de las familias. En concreto, el segundo apartado describe los orígenes del sector en España, haciendo énfasis en la relación que existe entre estas entidades y el sector primario, al que financia de manera preferente. Posteriormente, tras describir las características del sector de cooperativas de crédito, el perfil de sus socios y las ventajas sobre otras formas bancarias, se exponen algunas causas que están provocando su transformación, sin perder de vista su orientación hacia el socio. Es por ello que, en la tercera sección de este trabajo se plantean las bondades que las cooperativas de crédito pueden ofrecer a la hora de limitar la exclusión financiera, máxime cuando se han convertido en el único exponente de la banca social en España, tras la desmutualización planificada del sector de cajas de ahorros.
\end{abstract}

Palabras clave: cooperativas de crédito españolas, exclusión financiera, financiación del sector primario, pautas de ahorro.

\section{Spanish Credit Cooperatives and the Fight against Financial Exclusion}

\begin{abstract}
The aim of this study is to show the importance of Spain's credit cooperative sector, while also offering a brief view of how families' savings patterns have evolved. The second section describes the origins of the sector in Spain, emphasizing the relationship between these entities and the primary sector, which is the main source of finance. Later, by describing the features of the credit cooperative sector, as well as offering a profile of its members and its advantages over other forms of banking, some causes are presented for the transformation of these cooperatives, a change they have undergone without losing their focus on members. Accordingly, the third section of this study presents the benefits that credit cooperatives can offer when it comes to financial exclusion, especially when they have become the only social bank in Spain due to the planned demutualization of the savings bank sector.
\end{abstract}

Keywords: Spanish credit cooperatives, financial exclusion, primary sector financing, savings patterns.

\section{As cooperativas de crédito espanholas e a luta contra a exclusão financeira}

Resumo

O objetivo deste trabalho consiste em apresentar a importância do setor de cooperativas de crédito na Espanha, ao mesmo tempo em que se oferece uma breve visão da evolução das pautas de poupança financeira das famílias. Em concreto, a segunda seção descreve as origens do setor na Espanha e enfatiza a relação existente entre essas entidades e o setor primário, ao qual financia de maneira preferente. Em seguida, após descrever as características do setor de cooperativas de crédito, o perfil dos seus sócios e as vantagens sobre outras formas bancárias, expõem-se algumas causas que estão provocando sua transformação, sem perder de vista sua orientação ao sócio. Na terceira seção deste texto, apresentam-se os benefícios que as cooperativas de crédito podem oferecer na hora de limitar a exclusão financeira, principalmente quando se converteram no único expoente da banca social na Espanha, depois da desmutualização planejada do setor de caixas de poupança.

Palavras-chave: cooperativas de crédito espanholas, exclusão financeira, financiamento do setor primário, pautas de poupança. 


\section{Introducción}

Resulta incuestionable la importancia que tiene la actividad bancaria para el correcto desarrollo de una economía, en tanto que es el nexo necesario para poner de acuerdo a los demandantes y oferentes de servicios financieros. Así, la existencia de las entidades de crédito está condicionada por la capacidad que tienen estas de reducir ciertos costes de transacción y de información, con el objeto de hacer fluir el crédito a las empresas, a la vez que canalizan el ahorro de las economías domésticas.

En el caso de España, el sector bancario se caracteriza por un perfil eminentemente minorista, con una tupida red de sucursales y la comercialización universal de servicios financieros. Se trata de un sistema bancario que alterna el negocio tradicional -en claro estancamiento debido a la tendencia a la contracción del crédito en los últimos años- con el crecimiento de la desintermediación, que ha provocado ciertos cambios en las pautas de inversión de los ahorradores, dando lugar a la aparición de un elevado número de partícipes en fondos de inversión. Así, en la figura 1 se muestra cómo ha evolucionado la distribución del ahorro financiero de los hogares en los últimos veinte años.

Resulta interesante el análisis de la predisposición al mantenimiento de dinero en efectivo en el horizonte temporal considerado (1990-2011). En este sentido, se constata cómo en la década del 2000 los ahorradores se interesaron por la contratación de títulos de renta variable, fondos de inversión y planes de pensiones. Este interés se hacía a costa de reducir su riqueza en efectivo y depósitos, pues era más interesante aprovechar las ventajas que reportaban las numerosas ofertas públicas de venta de acciones (opv) del momento. Además, en la década del 2000, España vivió una de las etapas doradas de su crecimiento económico, que supuso un cambio sustancial en las pautas de inversión de las familias, haciéndose más propensas a la especulación y al riesgo. En este escenario, las entidades bancarias no tuvieron más remedio que ampliar sus actividades, apostar por la intermediación financiera y por las nuevas figuras de inversión con el objeto de generar nuevas fuentes de ingresos.

Sin embargo, a finales del 2007, con el estallido de la crisis financiera mundial, que tanto ha afectado a las
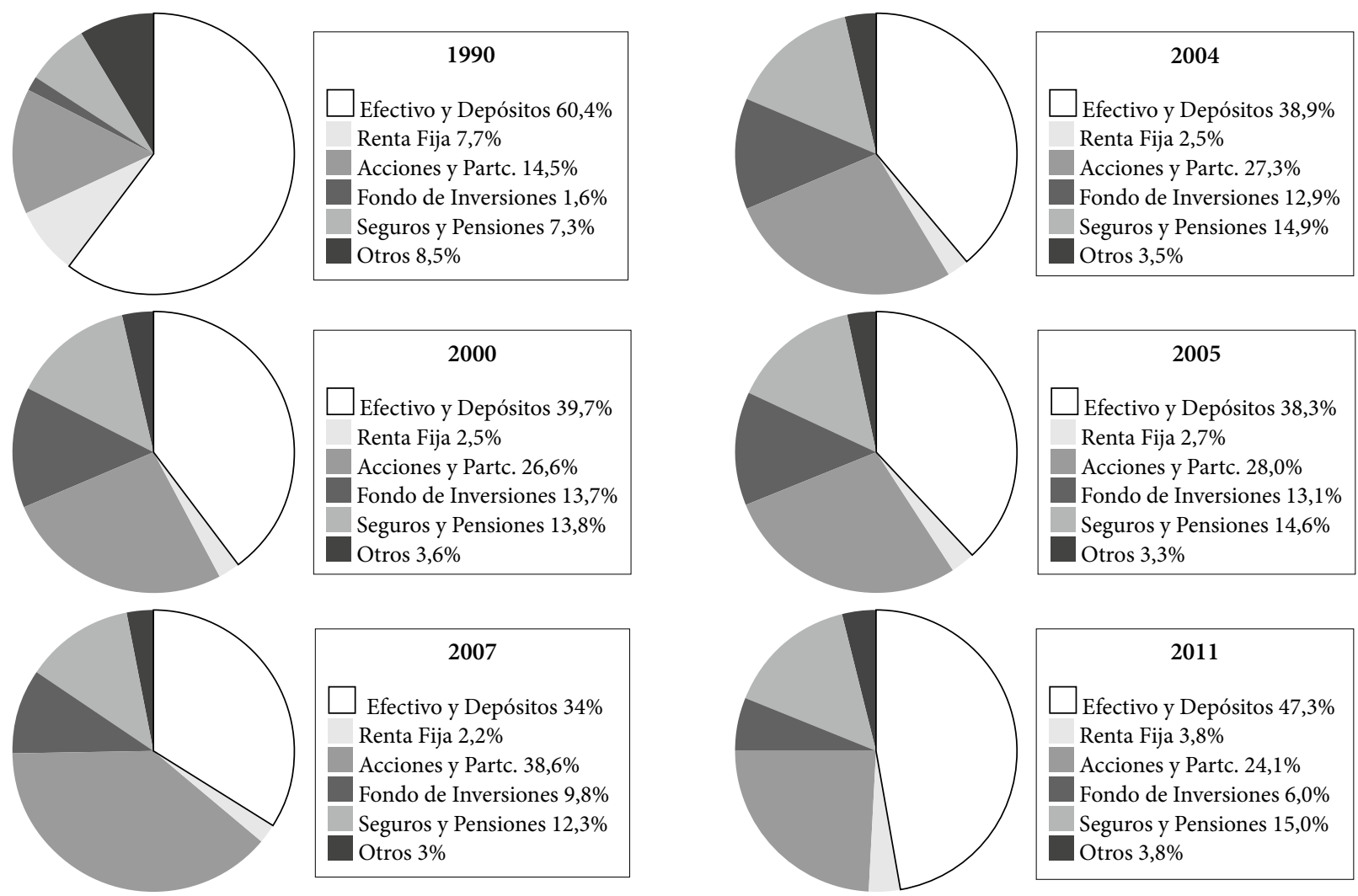

Figura 1. Evolución de la distribución del ahorro financiero de los hogares (1990-2011) Fuente: elaboración propia a partir de información del Banco de España, 2012 
macromagnitudes económicas de España, la predisposición a la inversión por parte de la clientela cambió radicalmente. Por un lado, las altas tasas de morosidad que se han registrado en España han provocado una importante contracción del crédito, que ha lastrado las cuentas de resultados de las entidades más activas en la concesión de préstamos, provocando importantes problemas de solvencia. Por otro lado, la clientela ha renovado el interés por mantener gran parte de su riqueza en forma de efectivo y depósitos, como vía para salvaguardar la integridad de sus ahorros, sin correr el más mínimo riesgo de inversión, aunque ello conlleve la pérdida de rentabilidad. En concreto, es la explicación más lógica al comportamiento que se detecta en la figura 1, entre el 2007 y el 2011, cuando la partida de efectivo y depósitos se incrementa desde el 34\% hasta el $47,3 \%$ del total de la riqueza financiera de las familias. Además, se observa cómo los ahorradores huyen de la inversión en acciones y participaciones, que pasan del $38,6 \%$ al $24,1 \%$.

Es indudable que la crisis financiera ha provocado un cambio importante en la clientela, que sufre una alta tasa de desempleo, 25,02\% según la Encuesta de Población Activa del tercer trimestre (INE, 2012). Además, la falta de empleo es la principal causante de la evolución de la tasa de morosidad del crédito al sector privado residente, que ha superado el $10 \%$, según la Asociación Hipotecaria Española (AHE, 2012). Evidentemente, el impacto en el negocio bancario no se ha hecho esperar, siendo la tónica habitual de todas las entidades bancarias el importante descenso en los beneficios, por la contracción del crédito, el deterioro de la solvencia, por la dotación de pérdidas por los crédito incobrables $y$, finalmente, el aumento desmesurado en el cobro de comisiones bancarias para compensar la pérdida de márgenes de negocio. Este renovado interés de las entidades bancarias por la rentabilidad es lo que puede estar ocasionando el aumento de la exclusión financiera, especialmente entre los clientes con menos recursos.

En este contexto, el objetivo de este trabajo consiste en presentar las bondades del sistema de cooperativas de crédito español, en un escenario macroeconómico marcado por la crisis, con altas tasas de desempleo, altos riesgos de insolvencia y la imparable desmutualización de las cajas de ahorros. En este marco, la estructura de este trabajo consiste en presentar, en el siguiente apartado, la importancia del sector de las cooperativas de crédito españolas, con relación al resto de intermediarios. Posteriormente, en el tercer apartado se analiza el papel que cumple este tipo de entidades a la hora de luchar contra la exclusión financiera, a la vez que contribuyen al desarrollo de los territorios en los que se asientan. Finalmente, se concluye con un apartado con las principales conclusiones de este trabajo.

\section{El sector de las cooperativas de crédito español. Un intermediario financiero válido}

Según el anuario de la Unión Nacional de Cooperativas de Crédito (UNACC), al cierre del ejercicio 2011, existían en España 74 cooperativas de crédito, de las que 66 revisten la forma jurídica de cajas rurales, y ocho son cajas populares o profesionales. A primera vista, llama la atención el elevado número de cooperativas de crédito, en comparación con el resto de intermediarios bancarios (148 bancos, entre nacionales e internacionales, y 11 cajas de ahorros), aunque muchas de ellas se encuentran inmersas en futuros procesos de concentración. A pesar del elevado número de cooperativas de crédito, su representatividad macroeconómica es baja, en comparación con las cajas de ahorros y los bancos, ya que sólo representan el 5,4\% del crédito otorgado a otros sectores residentes y el $6,4 \%$ de los pasivos captados a ese mismo colectivo.

Desde el punto de vista de su representatividad como sector, todas las cooperativas de crédito se agrupan en torno a la UnACC. Además, la mayoría de las cajas rurales se vinculan a la Asociación Española de Cajas Rurales (AECR), que se fundó en la década de los noventa con la intención de consolidar un proyecto común para el sector a escala nacional por medio del Grupo Caja Rural (Belmonte, 2007; Melián et al., 2006 y Palomo, 2000). Sin embargo, en los últimos años han surgido otras iniciativas de concentración del sector, alternándose las fusiones en toda regla con otra figura asociativa que requiere un menor grado de compromiso, al menos al principio, como es el Sistema Institucional de Protección (SIP) (Belmonte y Cortés, 2010).

El interés por incrementar el tamaño de la compañía, al tiempo que se consigue diversificar su negocio, será clave para entender los subsiguientes procesos de concentración del sector, en los próximos meses. En este sentido, la particularidad de las cooperativas de crédito, en las cuales los derechos políticos no son proporcionales a la participación en el capital social, sino que se aplica la máxima de un socio, un voto, no supondrá un obstáculo a la concentración del sector, ya que 
la amplia base social de este tipo de entidades apenas resulta relevante para influir en su gestión (Cortés y Belmonte, 2010). En este sentido, ya sea mediante la constitución de SIP, o mediante fusiones en sentido estricto, el sector tenderá a corto plazo hacia la concentración, previsiblemente tutelado por las entidades líderes.

El peso del sector, desde el punto de vista geográfico, se concentra en dos regiones españolas: Andalucía y País Vasco. En concreto, a finales del 2011, ambos territorios acumulaban más de la mitad del volumen de activos totales de las cooperativas de crédito españolas, aumentándose este liderazgo cada año. Esta polarización del crecimiento del sector se debe a la notable actividad de dos grandes cooperativas de crédito tan dispares como son la Caja Laboral Popular - con sede en Guipúzcoa (País Vasco), donde presta apoyo financiero al grupo empresarial Mondragón- y Cajamar Caja Rural, sociedad cooperativa, con sede en la provincia de Almería (Andalucía), que está estrechamente vinculada con el sector agrario de todas las provincias donde se asienta.

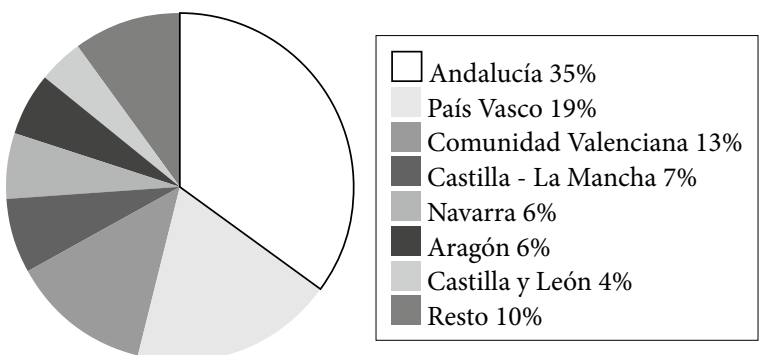

Figura 2. Volumen de activos totales del sector de cooperativas de crédito por comunidades autónomas españolas (2011) Fuente: elaboración propia a partir de información de la UNACC

A la vista de la figura 2, además de Andalucía y País Vasco, que aglutinan el 54\% de los activos del sector, también destaca la importancia que presentan otras regiones, como es el caso de la Comunidad Valenciana, Castilla-La Mancha, Navarra y Aragón. En este sentido, se trata de regiones cuyas cooperativas de crédito han sabido ocupar un lugar destacado en la financiación de las actividades productivas de sus territorios de influencia. Además, es en estas comunidades autónomas donde compiten con cierto éxito con el resto de intermediarios financieros, es decir, bancos comerciales y cajas de ahorros.

Es posible que en ciertas comunidades autónomas la opción financiera más aconsejable haya sido la elección de una cooperativa de crédito, por cuanto han sido las más activas en la concesión de créditos agrícolas, por ejemplo. Así, en un escenario marcado por una dura crisis económica, como la que sufre España desde finales del 2007, este tipo de entidades han sabido combatirla, aumentando el crédito a sus asociados, es decir, a agricultores y empresas del sector agroalimentario.

A este respecto, en la tabla 1 se presenta la evolución del endeudamiento del sector agrícola español según el tipo de entidad financiera que concede la financiación. En este sentido, es necesario tener presente que la concesión de créditos al sector agrícola reviste una serie de características que lo diferencian del resto de la inversión crediticia que realizan fundamentalmente bancos y cajas de ahorros. En concreto, la escasa dimensión de las explotaciones agrícolas, la falta de regularidad en los ingresos procedentes de la agricultura -que en muchos casos se producen varios meses después de haber solicitado la financiación, tras la fase de recolección de la cosecha, que además está sujeta a un elevado riesgo climático- exigen un conocimiento profundo del cliente a financiar.

A la vista de la tabla 1, se puede comprobar el equilibrio que existe en la financiación de la actividad agrícola en España, ya que se reparte casi a partes iguales, con una ligera inclinación hacia la financiación procedente de las cajas de ahorros. En este sentido, es preciso tener en cuenta que la cuota de mercado del sector de cooperativas de crédito en la financiación de actividades productivas en el ámbito agrícola - del $24 \%$ para el 2009- contrasta con la escasa representación que presentan las cooperativas en la financiación del resto de actividades productivas, ya que ostentan una cuota de mercado inferior al $6 \%$ del total de créditos a otros sectores residentes de la economía española. Sin embargo, la evolución desde el 2000 hasta el 2009 (último dato disponible con la desagregación por el tipo de intermediario bancario), indica que la línea de financiación que ha descendido en los últimos años ha sido la que procede del sector de cooperativas de crédito.

Un análisis más detallado de la estrategia comercial de las cooperativas de crédito (Belmonte, 2011; Cortes y Belmonte, 2010), nos lleva a pensar en la existencia de evidencias sobre el interés de este sector por incrementar su radio de acción a otras actividades distintas a las que originaron su aparición. Así pues, poco a poco, se han ido mimetizando con el resto de entidades bancarias, ofreciendo un amplio abanico de productos financieros, que poco las diferencian de otro tipo de entidades. Este interés por la banca universal, a la vez que se interesaban por clientes no vinculados 
Tabla 1. Evolución del endeudamiento del sector agrícola español según el tipo de intermediario

\begin{tabular}{|l|c|c|c|c|c|c|c|c|}
\hline \multirow{2}{*}{ Fuentes de financiación } & \multicolumn{2}{|c|}{$\mathbf{2 0 0 0}$} & \multicolumn{2}{c|}{$\mathbf{2 0 0 5}$} & \multicolumn{2}{c|}{$\mathbf{2 0 0 6}$} & \multicolumn{2}{c|}{$\mathbf{2 0 0 9}$} \\
\cline { 2 - 9 } & Valor & $\mathbf{\%}$ & Valor & \% & Valor & \% & Valor & \% \\
\hline Banca comercial & $6.040,8$ & 34,2 & $5.515,7$ & 30,0 & $6.516,6$ & 31,1 & $6.857,8$ & 37,0 \\
\hline Cajas de ahorros & $6.291,4$ & 35,6 & $6.940,8$ & 37,7 & $8.095,6$ & 38,7 & $8.514,9$ & 38,0 \\
\hline Cajas rurales/Coop. de crédito & $4.859,8$ & 27,5 & $5.655,4$ & 30,7 & $5.971,7$ & 28,5 & $6.915,7$ & 24,0 \\
\hline Crédito oficial y otros & 492,2 & 2,8 & 280,0 & 1,5 & 340,7 & 1,6 & 593,6 & 1,0 \\
\hline TOTAL & $\mathbf{1 7 . 6 8 4 , 2}$ & $\mathbf{1 0 0}$ & $\mathbf{1 8 . 3 9 1 , 9}$ & $\mathbf{1 0 0}$ & $\mathbf{2 0 . 9 2 4 , 6}$ & $\mathbf{1 0 0}$ & $\mathbf{2 2 . 8 8 2 , 0}$ & $\mathbf{1 0 0}$ \\
\hline
\end{tabular}

Fuente: elaboración propia a partir de los datos del Ministerio de Agricultura, Alimentación y Medio Ambiente

socialmente a ellas, ha provocado que muchas de ellas hayan traspasado sus límites territoriales, extendiendo su red de sucursales por otras provincias en las que la estrategia de comercialización era universal y la financiación de su actividad preferente era un producto más del amplio repertorio financiero con el que cuentan. El reto ahora es saber si mantendrán su sello social, su compromiso con sus territorios originarios y su apoyo a la lucha contra la exclusión financiera.

\section{Las cooperativas de crédito y la lucha contra la exclusión financiera}

La presión competitiva a la que se ven sometidas las entidades financieras como consecuencia del proceso de globalización, la desregularización del sector bancario y el desarrollo de las tecnologías de la información y la comunicación (TIC) han aumentado el interés por el diseño y la implementación de estrategias tendientes a la búsqueda de la eficiencia. Sin embargo, muchas entidades bancarias se han desorientado en sus planteamientos, pues la búsqueda de eficiencia las está convirtiendo en exclusivas, al menos para un sector de la clientela.

Así, una de las principales consecuencias de este proceso de universalización y extensión de los servicios bancarios, ha sido el desarrollo de planes de actuación basados en el perfil rentabilidad-riesgo de la clientela, discriminando de forma positiva aquellos segmentos capaces de generar un mayor valor añadido y marginando a aquellos clientes menos atractivos desde el punto de vista de la rentabilidad. Aquí comienza a aparecer la exclusión financiera.

Conceptualmente, la exclusión financiera se puede definir como el conjunto de dificultades de acceso a los servicios bancarios elementales, como son disponer de una cuenta para depositar los ahorros, poder efectuar transacciones con dicha cuenta o poder disfrutar de un crédito, por citar algunos, que se llevan a cabo con la única finalidad de hacer a la entidad más rentable desde el punto de vista económico. Además, en la medida en que encarezcan los servicios básicos o simplemente se nieguen a ciertos colectivos de la población, estaremos asistiendo a una situación de exclusión financiera.

Desde el punto de vista de su clasificación, la exclusión financiera puede presentarse de muchas maneras, a saber:

- Exclusión geográfica. Es aquella que hace mención a la falta de proximidad de una entidad financiera en el territorio, es decir, aquella que practican algunas entidades al evitar instalar sucursales en los lugares más recónditos, con menos posibilidades de desarrollo económico, peor comunicados, entre otros.

- Redlining. Es una forma de exclusión financiera basada en un scoring de riesgo, es decir, ocurre cuando una entidad no tiene en sus planes la inversión o captación de recursos en una determinada zona geográfica, porque está deprimida económicamente, aunque también se puede aplicar a un sector de la población, por presentar menores garantías de solvencia crediticia.

- Exclusión en el acceso. En estos casos, las entidades bancarias suelen descartar determinados clientes en función de su perfil individual de riesgo-rentabilidad. Además, a veces ni siquiera es necesario que el cliente plantee ninguna operación de financiación que genere riesgo de crédito para la entidad, ya que en muchos casos la exclusión se aplica porque el cliente en sí no presenta un volumen de recursos suficiente del cual obtener altas rentabilidades. En otros casos, esta exclusión se aplica por la falta de cierto estatus administrativo, como consecuencia, por ejemplo, de encontrarse residiendo de manera irregular en el país.

- Exclusión comercial. Surge cuando se deja al margen de las estrategias de venta y marketing a determinados individuos. Por ejemplo, se excluye de ciertas bonificaciones a una parte de la clientela. 
En definitiva, la exclusión financiera es un problema que está muy presente en la actualidad y es posible que aumente en los próximos meses. En este sentido, cada vez es más probable que se incrementen las dificultades de acceso de ciertos colectivos a los productos financieros básicos como es el caso de:

- Las crecientes dificultades para poseer una cuenta bancaria sin costes financieros, por lo que se impediría el ahorro financiero, la transferencia de fondos, la emisión de medios de pago, etc.

- El riesgo elevado en el que pueden caer determinados colectivos al tener que acudir a "prestamistas sin estatus".

- La exclusión en el ámbito de los seguros se vuelve más problemática cuando se extienden las posibilidades de cobertura del riesgo.

- La aparición de nuevos canales de distribución que exigen cierto desarrollo cultural (banca por Internet $y$ tarjetas).

- Restricción de horarios en tareas administrativas poco rentables (operaciones de ventanilla) o en municipios poco poblados.

Afortunadamente, hasta ahora, de los tres tipos de intermediarios bancarios que existen, las cooperativas de crédito y las cajas de ahorros son las que contribuyen con mayor énfasis a mitigar los efectos de la exclusión financiera. Es lo que se extrae tras observar la figura 3. La información de estas figuras se ha organizado teniendo en cuenta el crecimiento en la instalación de sucursales bancarias de los tres tipos de intermediarios bancarios: bancos comerciales, cajas de ahorros y cooperativas de crédito, teniendo en cuenta el tipo de municipio en el que se instalan. Así, se constata que las entidades de depósito de tipo social, como las cajas de ahorros y las cooperativas de crédito, son las más activas en la instalación en todos los ámbitos, es decir, no sólo en los municipios grandes (con más de 10.000 habitantes), sino también en los más reducidos (con menos de 10.000 habitantes).

Sin embargo, aunque todavía es notorio el crecimiento en la instalación de sucursales de las entidades sociales en los municipios menos poblados, es evidente que a la hora de asentarse han preferido las grandes poblaciones. La banca comercial, tanto en municipios grandes como pequeños, lleva una década amortizando sucursales, por lo que sería un claro ejemplo de una estrategia basada en la búsqueda de la rentabilidad económica.

Finalmente, en los últimos meses, España está asistiendo a un importante proceso de reconversión financiera que se centra en la ganancia de solvencia y que, indirectamente, está provocando la conversión de las cajas de ahorros en sociedades por acciones. Es por ello que, en el futuro, el único exponente de banca social en España será el que constituya el sector de cooperativas de crédito, que por ahora no ha sucumbido a la corriente desmutualizadora que afecta las cajas de ahorros.
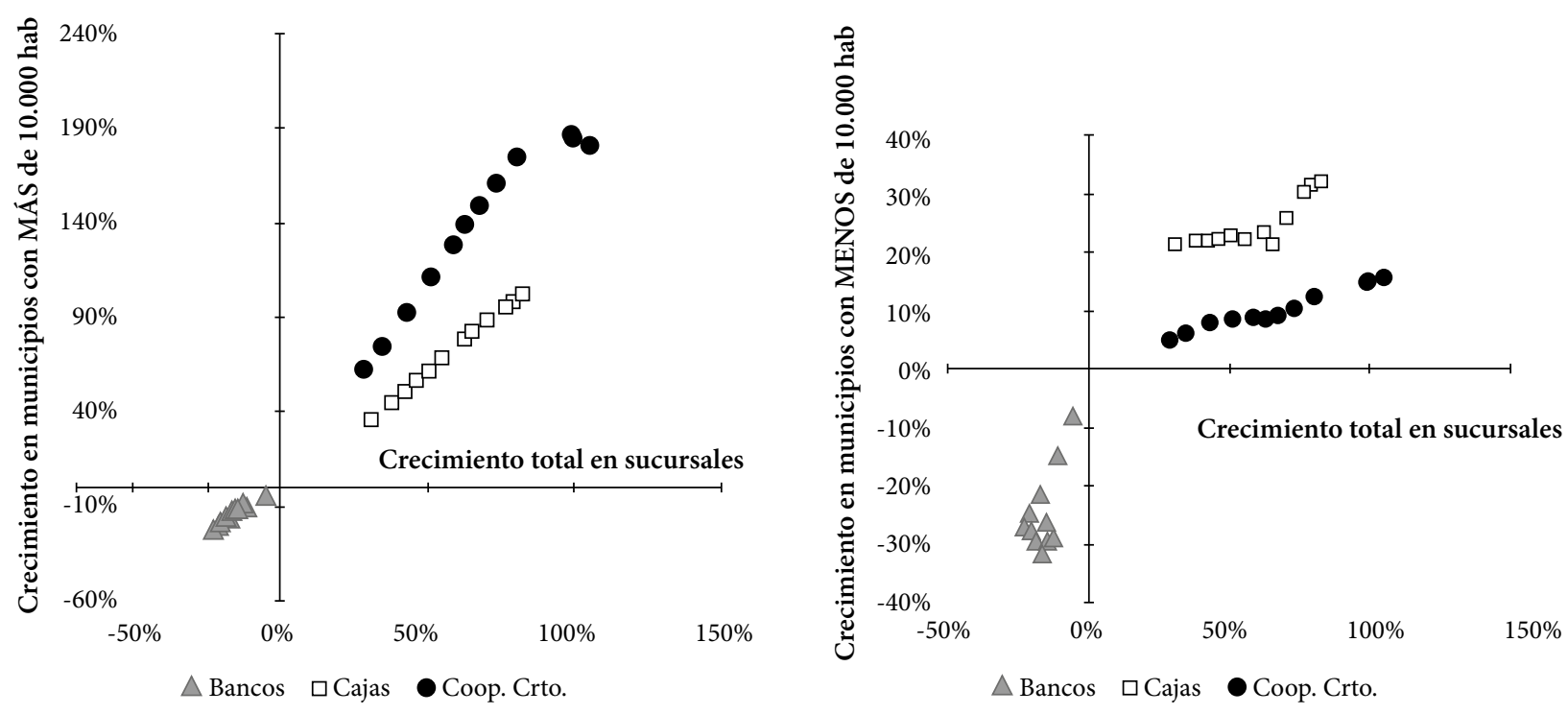

Figura 3. Intensidad en el crecimiento de sucursales en función del tamaño del municipio (2000-2011) Fuente: elaboración propia, con información del INE y el Banco de España 


\section{Conclusiones}

Es un hecho que en las dos últimas décadas se ha producido un cambio sustancial en las pautas de ahorro financiero de las familias, que comenzaron a interesarse masivamente por nuevas figuras de inversión financiera, como son los fondos de inversión, la compra de acciones en bolsa y los planes de pensiones. Así, todas las entidades comenzaron a ampliar su oferta de productos y de servicios financieros, por lo que universalizaron cada vez más su actividad. Sin embargo, a finales del 2007, con la crisis financiera, la aventura inversora de la clientela dio paso a una nueva fase de preferencia por la liquidez, que no es más que un reflejo de la pérdida de confianza en los intermediarios financieros.

En este marco, las cooperativas de crédito, como máximo exponente de la banca social en España, no han tenido más remedio que adaptarse a los nuevos requerimientos de sus clientes, con una demanda cada vez más variada, al tiempo que aprovechaban el cambio para extender sus actividades a otros territorios y a otro tipo de clientes, no socios. Además, con el advenimiento de la crisis, la fortaleza de su negocio original, es decir, el sector primario, las sitúa en mejores condiciones de solvencia que el resto de intermediarios: banca comercial y cajas de ahorros. Sin embargo, a pesar de su robustez como sector, no quedan al margen de la larga crisis por la que atraviesa España, por lo que han tenido que acometer estrategias para contrarrestar la crisis. Es por ello que la mayoría de las cooperativas de crédito españolas han iniciado procesos de concentración, con el fin de ganar dimensión y solvencia.

Desde el punto de vista de su representatividad como sector, las cooperativas de crédito no alcanzan a equipararse con el resto de entidades bancarias, al menos en cuota de mercado, pues representan algo menos del $6 \%$ del sistema bancario español. Sin embargo, sí que es importante el papel que cumplen estas entidades a la hora de financiar el sector primario, en el que se equiparan con los bancos comerciales y con las cajas de ahorros, lo que demuestra el papel tan importante que cumplen estas entidades, tan comprometidas con sus socios.

Finalmente, nuestro trabajo también aporta evidencias interesantes en el marco de la lucha contra la exclusión financiera. En concreto, además de las ventajas que reporta esta forma bancaria para sus socios, es decir, los cooperativistas, es un hecho que en el futuro el único exponente de la banca social en España lo constituirán las cooperativas de crédito. Así, en un futuro próximo, en el que las cajas de ahorros se hayan desmutualizado por completo para convertirse en sociedades por acciones, con la finalidad principal de la rentabilidad, las cooperativas de crédito seguirán presentes, prestando un servicio preferente a sus socios y desde la cercanía que supone estar instaladas en pequeños municipios, a veces olvidados para la gran banca comercial.

\section{Referencias}

Asociación Hipotecaria Española (AHE). (2012). Tasas de dudosidad hipotecaria. Segundo trimestre de 2012. Madrid. Recuperado de http://www.ahe.es.

Banco de España. (mayo 2012). Boletín Estadístico del Banco de España.

Belmonte, L. J. (2007). El sector de cooperativas de crédito en España. Un estudio por Comunidades Autónomas. Consejo Económico y Social de Andalucía, Colección Premio de Investigación, Sevilla.

Belmonte, L. J. (2011). El nuevo modelo de negocio de las cooperativas de crédito españolas. Perspectivas futuras. Papeles de Economía Española, 130, 54-67.

Belmonte, L. J. y Cortés, F. J. (2010). La concentración del sector de cooperativas de crédito en España. Revista de Economía Pública, Social y Cooperativa, 68, 223-246.

Cortés, F. J. y Belmonte, L. J. (2010). La base social de las cooperativas de crédito. La importancia de la responsabilidad social corporativa. Revista de Estudios Empresariales. Segunda época, 2, 35-53.

Ministerio de Agricultura, Alimentación y Medio Ambiente. (Varios años). Anuario de Estadística Agroalimentaria y Pesquera. Madrid: Subsecretaría Técnica,

Instituto Nacional de Estadística (INE). (2012). Encuesta de Población Activa (EPA). Tercer trimestre de 2012. Madrid. Recuperado de http://www.ine.es/daco/daco42/ daco4211/epa0312.pdf

Melián, A.; Palomo, R. J.; Sanchis, J. R. y Soler, F. (2006). La investigación en materia de cooperativas de crédito y de grupos cooperativos. Revista de Economía Pública, Social y Cooperativa, 56, 25-64.

Palomo, R. J. (2000). Pasado, presente y futuro de la banca cooperativa en España. Ciriec-España, Valencia.

Unión Nacional de Cooperativas de Crédito. (Varios años). Anuario de las Cajas Rurales, Populares y Profesionales. Madrid: Servicio de Estudios de la UNACC. 